\title{
Reformulação do projeto editorial da Revista Informação na Sociedade
}

\section{Contemporânea}

\author{
Reformulation of the editorial project of the Magazine Informação na Sociedade Contemporânea \\ Reformulación del proyecto editorial de la Revista Informação na Sociedade Contemporânea
}

Recebido: 01/11/2021 | Revisado: 06/11/2021 | Aceito: 07/11/2021 | Publicado: 09/11/2021

Tarcísio Medeiros da Silva

ORCID: https://orcid.org/0000-0002-4884-8882 Universidade Federal do Rio Grande do Norte, Brasil E-mail: tmtarcisiomdasilva@gmail.com

Gustavo Luís Bezerra de Medeiros

ORCID: https://orcid.org/0000-0001-8695-8727 Universidade Federal do Rio Grande do Norte, Brasil E-mail: Gustavopes032015@gmail.com

\begin{abstract}
Resumo
Este trabalho apresenta as sugestões para o processo de reformulação do projeto editorial da Revista Informação na Sociedade Contemporânea (RISC), periódico científico ligado ao Departamento de Ciência da Informação (DECIN) e ao Programa de Pós-.Graduação em Gestão da Informação e do Conhecimento da Universidade Federal do Rio Grande do Norte (UFRN). Objetivando determinar quais os elementos que deverão conter o projeto e qual política deve ser apresentada para que venha a ser um canal de desenvolvimento nesse tipo de publicação, comparar as políticas e processos editoriais da RISC com as de outros conceituados periódicos da área da Ciência da Informação, identificando e indicando as boas práticas editoriais para que elas sejam aplicadas. A análise comparativa se dará com as revistas: Informação \& Sociedade, Perspectivas em Ciência da Informação e Transinformação.
\end{abstract}

Palavras-chave: Projeto editorial; Periódico científico; Reformulação; Políticas editoriais; Ciência da informação.

\begin{abstract}
This paper presents suggestions for the process of reformulation of the editorial project of the Information Society in Contemporary Society (RISC), a scientific journal linked to the Department of Information Science (DECIN) and the Post-Graduation Program in Information and Knowledge Management of the Federal University of Rio Grande do Norte (UFRN). In order to determine the elements that the project should contain and which policy should be presented to be a development channel in this type of publication, compare RISC's editorial policies and processes with those of other leading journals in the area of Information Science, identifying and indicating good editorial practices for them to be applied in the RISC. The comparative analysis will take place with the magazines: Informação \& Sociedade, Perspectivas em Ciência da Informação and Transinformação.
\end{abstract}

Keywords: Editorial project; Scientific journal; Reformulation; Political editorials; Information science.

\section{Resumen}

Este trabajo presenta sugerencias para el proceso de reformulación del proyecto editorial de la Revista Informação na Sociedade Contemporânea (RISC), revista científica vinculada al Departamento de Ciencias de la Información (DECIN) y al Programa de Posgrado en Gestión de la Información y el Conocimiento de la Universidad Federal. de Rio Grande do Norte (UFRN). Con el objetivo de determinar qué elementos debe contener el proyecto y qué política se debe presentar para que se convierta en un canal de desarrollo en este tipo de publicaciones, comparar las políticas y procesos editoriales de RISC con los de otras revistas de renombre en el campo de las Ciencias de la Información, identificando e indicando buenas prácticas editoriales para su aplicación en RISC. El análisis comparativo se realizará con las revistas: Information \& Society, Perspectives on Information Science and Transinformation.

Palabras clave: Proyecto editorial; Periódico científico; Reformulacion; Políticas editoriales; Ciencias de la informacion.

\section{Introdução}

A informação vem através dos séculos apresentando um nível excepcional de importância para a sociedade, sendo até hoje considerada um dos patamares essenciais para o desenvolvimento da sociedade humana, principalmente com a globalização. Com o advento das tecnologias existentes, a mensagem é compartilhada de forma instantânea em todas as partes do 
mundo, tudo se transforma em informação. Por isso é importante que ela seja disponibilizada de forma que possa ser encontrada com facilidade. No cerne da questão, encontram-se os periódicos científicos, sejam eles digitais ou físicos.

Os periódicos, no meio científico, por serem veículo de fácil circulação, são a principal forma de comunicação entre os produtores do conhecimento. É por meio deles que os avanços da Ciência são levados a público, permitindo a visibilidade e disseminação das novas descobertas. Para Bomfá (2009), as tecnologias de informação e comunicação presentes, inseridas na sociedade do conhecimento, têm propiciado maior acesso às informações a públicos mais amplos e não somente os ligados à academia, bem como novas formas de divulgar a ciência. Para Medeiros e Medeiros (2021), as questões acerca da educação afetam a população como um todo, sendo por isso pertinente o debate do tema, de acordo com o que há publicado. Assim os periódicos possuem função prestigiosa, pois é por meio deles que são divulgadas as inovações e resultados de pesquisas nas variadas áreas do conhecimento científico e de forma contínua. Para Packer (2011), o caráter científico dos periódicos é o resultado de trabalhos originais que são submetidos e aceitos, após serem revisados por avaliadores e que também atenda às políticas editoriais.

Em razão da importância crescente da publicação científica em todas as áreas do conhecimento, os periódicos são obrigados, cada vez mais, a obter altos padrões de qualidade, para que possam atrair autores de bons artigos, resultando em maior número de leitores interessados. As publicações científicas são consideradas como elemento final no ciclo da busca pela informação, transformando-se em um indicador qualitativo para a construção da confiança e credibilidade para todos os envolvidos nesse processo de propagação e desenvolvimento em determinada área específica do conhecimento científico.

Apresentando as mais variadas definições, o periódico científico nada mais é do que uma publicação periódica que veicula artigos e notícias sobre pesquisas desenvolvidas em um campo científico específico. De acordo com a Associação Brasileira de Normas Técnicas (2003), uma publicação periódica é:

Um dos tipos de publicações seriadas, que se apresenta sob a forma de revista, boletim, anuário etc., editada em fascículos com designação numérica e/ou cronológica, em intervalos pré-fixados (periodicidade), por tempo indeterminado, com a colaboração, em geral, de diversas pessoas, tratando de assuntos diversos, dentro de uma política editorial definida, e que é objeto de Número Internacional Normalizado (ISSN). (Associação Brasileira de Normas Técnicas, 2003, p. 2)

Parte integrante dos periódicos científicos, a publicação de artigos científicos busca submeter os novos conhecimentos produzidos em sua área específica, ao julgamento dos pares, criando comunidades de interesse em torno de determinados assuntos de interesse comum em sua área de atuação. A partir de uma análise vista pelo lado social, torna-se de grande importância para os praticantes da ciência que visam a garantia do reconhecimento dos pares assegurando a precedência na autoria delas.

A importância das revistas científicas é tão acentuada que Gargantini (1997, Apud Andre 2012) afirma:

O periódico ou revista científica é o principal veículo de comunicação científica dadas suas características de síntese de conteúdo e facilidade de produção e distribuição. Através de sua política editorial, funciona como filtro de qualidade no processo de seleção de artigos a serem publicados; é, também o principal veículo para o registro do conhecimento e o único capaz de atingir, dado seu caráter válido e permanente, grande número de leitores. (Andre, 2012)

Tendo em vista a importância do periódico, Souza (2009, p. 23) chama atenção:

[...] nos pontos relacionados à recuperação, ao acesso e à disseminação da informação científica, os periódicos científicos vêm sendo de extrema relevância, com o diferencial de possuir dados mais atualizados, se comparados com outros canais formais de comunicação científica. Os periódicos científicos são publicações seriadas e com periodicidade determinada e tais fatores conferem mais atualidade à disseminação científica. (Souza, 2009) 
Porém, os artigos científicos são atualmente considerados também como algo possível de ser comercializado pelas grandes editoras científicas comerciais que a partir do momento em que adquirem os direitos de publicação de grande parte do que é produzido no mundo científico, criam um monopólio nesta área do conhecimento, vendendo as assinaturas dos periódicos para as universidades e institutos de pesquisa e demais pesquisadores interessados.

Do ponto de vista dos autores, as expectativas incluem avaliação rápida, detalhada, criteriosa e justa; editoração correta e fiel ao seu texto; rapidez na publicação; e impacto acadêmico e/ou social da publicação. Esse conjunto de expectativas depende fundamentalmente da qualidade do artigo e dos processos editoriais das revistas e são por esses motivos que os periódicos são obrigados, cada vez mais, a obter padrões de qualidade elevados, para que possam conquistar bons autores, resultando em maior público interessado.

\subsection{Revista Informação na Sociedade Contemporânea (RISC)}

A Revista Informação na Sociedade Contemporânea (RISC) é uma publicação vinculada ao Departamento de Ciência da Informação e ao Programa de Pós-Graduação em Gestão da Informação e do Conhecimento, da Universidade Federal do Rio Grande do Norte (UFRN). Foi criada com o objetivo de se configurar como um canal de socialização dos resultados de estudos e pesquisas realizados na área de Ciência da Informação. Aberto às diversas correntes de pensamento acerca do fenômeno informacional nos mais diferentes segmentos sociais, dando preferência a artigos originais, resultados de estudos e pesquisas. Aprovada institucionalmente no ano de 2013 pelo conselho gestor do Portal de Periódicos da UFRN, a revista iniciou como uma publicação do Grupo de Pesquisa "Informação na Sociedade Contemporânea" privilegiando os temas vinculados às grandes áreas de suas linhas de pesquisa: Estudos Métricos da Informação em Ciência, Tecnologia e Inovação; Inteligência Competitiva, Empreendedorismo e Redes Sociais; Organização e Tratamento da Informação; Redes e Transferência da Informação.

Com a implementação do Mestrado Profissional em Gestão da Informação e do Conhecimento do PPGIC, o escopo da RISC se ampliou, abrangendo também os estudos e pesquisas desenvolvidos neste âmbito, promovendo também a publicação de resenhas, livros e os resumos de monografias, teses e dissertações dos cursos de graduação e pós-graduação vinculados ao Departamento de Ciência da Informação da UFRN. No processo de avaliação pelos pares, os originais são submetidos à aprovação de especialistas reconhecidos nos assuntos abordados. Os assuntos tratados são enviados sempre para dois ou mais especialistas na área, sempre de acordo com a necessidade exigida pela temática, não sendo identificada a sua autoria, a fim de garantir um parecer isento de alguma forma de influência. Em seguida à avaliação, os escritos caso sejam aprovados, serão encaminhados ao Comitê Editorial, que se responsabilizará pela seleção dos artigos a serem publicados. Esse processo de seleção de artigos para publicação conta com a avaliação de dois ou mais especialistas, além de membros do Comitê Editorial, ficando para o editor científico a responsabilidade de tirar todas as dúvidas e impasses existentes para que possa tomar a decisão final sobre a edição.

Os leitores da RISC contam com acesso livre e imediato ao seu conteúdo, pois o periódico segue o princípio de que disponibilizar gratuitamente o conhecimento científico ao seu público leitor, é uma forma de proporcionar o acesso à intelectualidade científica em sua área específica de atuação.

Não se pode deixar de lado também a opinião formada pelos leitores, quanto às suas expectativas, que estão sempre ligadas à importância e à atualidade dos temas abordados, seu caráter inovador dos artigos publicados, apresentando textos bem escritos e com sua devida clareza.

No caso específico, que visa a reformulação da RISC, deve-se focar, entre outros, em um sistema moderno informatizado, adotando o uso de ferramentas que tornem mais rápida a avaliação e facilite a pré análise de quais os elementos serão necessários para que o projeto de políticas editoriais da RISC venha se adequar às normas internacionais de fazer e comunicar a pesquisa científica. 


\subsection{A importância de um Projeto Editorial}

Um projeto editorial é um documento norteador para a editoração e é a partir dele que são definidas as características, tipos de conteúdo e planejamento para a uma publicação. Pode ser feito para qualquer tipo de produto, como livros, revistas, jornais etc. É essencial para manter as características e objetivos ao longo do tempo, mesmo em casos em que membros da equipe são substituídos, garantindo a consistência da marca. Segundo Carvalho (2010), toda revista possui um projeto editorial que serve como diretriz e ponto de acesso ao seu público leitor. É este projeto que determina as abordagens realizadas pelo veículo, os temas pautados e as suas intenções.

É de suma relevância para o sucesso de qualquer periódico, pois é nele que encontramos os direcionamentos necessários para que o desenvolvimento do trabalho de cada membro da equipe seja realizado da forma mais satisfatória possível. É importante a adoção de um projeto editorial bem formulado, já que ele servirá como documento norteador do perfil e das políticas editoriais a serem adotadas pelo periódico. Segundo Araújo (1991, p. 37): "O poder da informação (...) tem capacidade ilimitada de transformar culturalmente o homem, a sociedade e a própria humanidade como um todo." É nesse documento que são definidas quais as características e os tipos de conteúdo e o planejamento a ser adotado para uma determinada publicação. Deve ser feito em qualquer produto, como: livros, revistas eletrônicas, jornais, entre outros, sendo também de fundamental importância para que as características e objetivos a serem alcançados pelo periódico sejam mantidos ao longo do tempo.

“a editoração, entretanto, vai além: ademais da forma original, da reconstituição, da fidedignidade, da preservação dessa forma literária, pressupõe, como dado igualmente importante, o suporte material com que se apresentará o texto restaurado por inteiro (ou, no caso de um escritor vivo, sobretudo em ensaio ou monografia, corrigido e normalizado), de modo a não trair - ao contrário, preservar, ressaltar - o pensamento do autor.” (ARAÚJO, 2008, p. 53).

Dentre os itens necessários para a sua criação, estão as definições de formatos usados, fontes, imagens e outras orientações gráficas que impactam diretamente no resultado do trabalho. Esses elementos compõem a parte de design do produto e são tão importantes quanto seu conteúdo.

O projeto editorial é um documento norteador e é composto pelos seguintes itens:

- Título: Deve ser muito bem pensado, para que a publicação consiga envolver o público;

- Missão: Com que objetivo está sendo criado aquela publicação? O que pretendo conseguir com ela?

- Público-alvo: A quem essa publicação é direcionada? É preciso pesquisar sobre os interesses e as características principais desse público. Essa parte precisa conter uma descrição do perfil do público a ser atingido.

- Política Editorial: Qual é a linha editorial da publicação? O que ela permite e o que não permite? Temática, estrutura;

- Distribuição: Onde e em que formatos se distribuirá;

- Divulgação: Em qual canal será publicado;

- Equipe: Quantos profissionais são necessários e a responsabilidade de cada um;

- Modelo de financiamento: Como será a sustentação financeira da publicação;

- Projeto gráfico: É a identidade visual da publicação;

- Linguagem e Fontes: Qual a linguagem e as fontes do conteúdo;

- Tema: Qual tema será abordado?

- Periodicidade: Qual a frequência anual das edições.

As vantagens de investir na criação de um projeto editorial são muitas, a exemplo de um maior foco e clareza dos assuntos abordados pela comunicação da empresa e o agrado ao público-alvo, que devido à relevância e consistência da marca, sente-se mais atraído pela sua mensagem. 


\subsection{Tendências do Setor Editorial Contemporâneo}

O campo de edição vem experimentando há várias décadas uma revolução constante em consequência do avanço acelerado das novas tecnologias de informação, comunicação e impressão.

Essa revolução tem alcançado todos os aspectos da atividade editorial, que deixou de ser uma atividade exclusiva de certas Instituições com grandes recursos - apesar do processo de monopolização intenso que ocorre atualmente entre as grandes editoras - tornando-se uma atividade que a grande maioria pode realizar com bastante independência.

O percurso pelo qual se estabelece o conhecimento científico compreende: a produção, a comunicação e a aplicação do conhecimento gerado. Nesse processo, a publicação científica exerce função essencial, na medida em que viabiliza a divulgação dos resultados de pesquisa e promove a discussão. Por um lado, a construção do conhecimento científico depende do espalhamento e da transferência das informações, com o intuito de consolidar novos conceitos, por outro, o processo interativo de discussão e a aprovação pelos cientistas garantem confiabilidade às pesquisas. Transformações e inovações estão ocorrendo no que diz respeito à produção, transmissão e uso do conhecimento, dissociando-se dos suportes tradicionais como livros impressos, periódicos e jornais (Rosetto, 1997). A autora explica que estas modificações oportunizaram tanto ao produtor quanto ao receptor da informação uma "associação de formatos e gêneros, categorias de discursos", além de uma diversidade de materiais informacionais.

Sendo assim, faz-se necessária a busca por novos conhecimentos e desenvolvimento de novas técnicas de gestão do trabalho editorial com novas habilidades, atitudes e motivações para que venha a funcionar com sucesso em um contexto concreto.

No campo da produção, Bomfá (2009) indica que se destaca como aspecto inovador a transição da comunicação impressa para a eletrônica, mencionada por: Meadows (2001), Gomes (1995), Lemos (2005), Weitzel (2005).

As tecnologias de informação e de comunicação, mediadas por computador, provocam mudanças significativas nas atividades de pesquisa, desenvolvimento e inovação, e consequentemente, na produção, armazenamento, divulgação, recuperação e atualização das publicações científicas. As modificações trouxeram desafios para a área da comunicação científica, envolvendo alteração de hábitos e práticas, no que se refere aos processos de produção e transmissão do conhecimento em meios digitais. A publicação científica divulgada na Internet comprova as mudanças ocasionadas pelas inovações tecnológicas, consequência da evolução das publicações impressas para o meio eletrônico. O processo de produção, distribuição e consumo dos periódicos científicos, inerentes ao modelo clássico, incorporados pelo suporte eletrônico, ocasionam alterações tanto no mercado editorial da comunicação científica, quanto nas estratégias de visibilidade do conhecimento. (Weitzel, 2005)

\subsection{Avaliação em periódicos}

A publicação por si só não tem validade científica se não for avaliada, reconhecida e aceita pelos pares, sendo que este processo surgiu em detrimento do grande número de artigos gerados e comercializados a partir do século XX. O processo de avaliação consiste, portanto, no encaminhamento do artigo para no mínimo dois avaliadores e para um terceiro, no caso de não haver consenso. O critério "cientificidade" de um artigo depende da aprovação e da avaliação criteriosa dos referees(árbitros), os quais atestam a originalidade e a qualidade dos trabalhos submetidos para publicação. Neste sentido, considera-se que o prestígio de um periódico científico depende da originalidade dos artigos, do reconhecimento científico, e do número de citações que seus artigos recebem. Este procedimento será tratado nos itens a seguir e baseia-se nos métodos ditados pelos órgãos certificadores da qualidade científica, dentre os quais o ISI, o SciELO e o Qualis.

O periódico científico caracteriza-se por apresentar comunicação rápida e precisa das pesquisas, o qual permite a troca de ideias entre os cientistas em determinados assuntos, sendo um novo meio de divulgar a ciência, pois é abrangente e eficaz, comparando-se, respectivamente, à correspondência pessoal e aos livros (Muller 2003 apud Bomfá 2009). 
Com base nos conceitos apresentados pelos autores entende-se que o periódico científico, ou técnico-científico, é uma publicação seriada, com periodicidade definida, cujo objetivo é oferecer ao autor registro, disseminação e recuperação das pesquisas mediante serviços de indexação e mecanismos de busca, bem como o reconhecimento e prestígio profissional. O caráter científico se dá mediante a aprovação e o reconhecimento dos pares.

Uma maneira de avaliar a qualidade de um periódico científico consiste em medir o interesse pela publicação. Para obter esta medida, o método se dá por meio da quantidade de citações da pesquisa (Meadows, 1999). Dentre os quesitos relevantes para a qualidade de um periódico estão: a publicação de bons artigos, corpo editorial reconhecido, periodicidade regular, abrangência do acesso aos artigos, os quais possibilitam a inclusão em bases indexadas, ampliando sua visibilidade. Mueller (1999) esclarece que a visibilidade científica amplia as chances de citações. Além de promover financiamento aos periódicos que publicam bons artigos, que são indexados e citados, ou seja, com boa reputação. A qualidade, portanto, relacionase às expectativas dos usuários, os quais avaliam com criticidade o rigor metodológico do conteúdo, bem como a apresentação, de acordo com os "ritos e rigores da comunidade científica" (Barbalho, 2005, p.134).

\subsection{A base Qualis - CAPES}

Como parte de um esforço para aperfeiçoar o sistema de avaliação da pós-graduação brasileira, a Capes, em 1998, propõe o desenvolvimento da base Qualis. Em relação às revistas científicas, o objetivo da Capes foi:

“[...] construção de indicadores de produção científica. fundamentados na qualidade das revistas utilizadas pelos programas de pós-graduação, devendo estas receber uma classificação conforme critérios definidos pelas comissões de áreas". Inicialmente, foram reunidos todos os veículos utilizados pelos programas de pós-graduação nacionais a partir dos relatórios que estes enviam à Capes. A seguir, essas publicações foram avaliadas conforme critérios definidos para cada área do conhecimento (SOUZA, 2002, p.8).

Atualmente, o Qualis-Periódicos é definido como:

"[...] o conjunto de procedimentos utilizados pela Capes para estratificação da qualidade da produção intelectual dos programas de pós-graduação". Anualmente, a Capes divulga uma lista com a classificação dos periódicos em cada área, enquadrando-os em estratos indicativos da qualidade - A1, o mais elevado; A2; B1; B2; B3; B4; B5; C - com peso zero. Um mesmo periódico pode ser classificado em mais de uma área, recebendo avaliações diferentes. Pode-se consultar a classificação de um periódico por meio do aplicativo Web Qualis (CAPES, 2015).

A Capes gerencia um sistema de avaliação das publicações periódicas denominado de Qualis, o qual constitui instrumento para ação direta no contexto da comunidade acadêmica, na busca de padrão de excelência para os programas de pósgraduação. Para fazer parte do Qualis, um periódico ou evento precisa ser citado pelos programas de pós-graduação como veículo de divulgação de sua produção e, além disso, ser indicado pelas áreas para figurar na sua tabela de referência.

O Qualis é o resultado do processo de classificação dos veículos utilizados pelos programas de pós-graduação, para a divulgação da produção intelectual de seus docentes e discentes. Tal processo foi concebido pela Capes para atender às necessidades específicas do sistema de avaliação e baseia-se nas informações fornecidas pelos programas, pela Coleta de Dados. O sistema baseia-se em informações fornecidas pelos programas de pós graduação, sendo que os periódicos são classificados, anualmente, por representantes de áreas, por âmbito de circulação internacional, nacional, local e por qualidade conforme os conceitos " $\mathrm{A}$ " alta, "B" média, ou "C" baixa.

Para pertencer ao Qualis o periódico precisa apresentar registro no ISSN; publicar as normas editoriais para submissão dos artigos; um conselho editorial com os nomes dos referees; manter periodicidade constante; artigos resultantes de pesquisas científicas, autores vinculados a diversas instituições. (Web Qualis 2007). 
Desde abril de 2008, a classificação dos periódicos divulgados no Qualis das áreas passou a ser composta de oito estratos, a saber: A1 (o mais elevado), A2, B, 22 WebQualis - http://qualis.capes.gov.br/webqualis/ 53 B2, B3, B4, B5, C (com peso zero), deixando de existir as categorias de circulação internacional, nacional e local (Web Qualis 2008).

\subsection{Problema de pesquisa}

Com as mudanças, já citadas anteriormente, ocorridas no contexto editorial mundial e nacional, são exigidas grandes e urgentes alterações na forma e no sentido de atualizar e readequar as políticas e perfil das revistas.

Diante desse contexto, quais seriam os elementos necessários para um projeto de reformulação das políticas editoriais da RISC, de forma que ela sofra uma adequação às normas internacionais de políticas editoriais de comunicação da pesquisa científica? Passando assim a atuar de forma a atrair cada vez mais autores conceituados, adotando medidas de boas práticas editoriais e antiplágio, com foco na ética da publicação analisando sempre quais os elementos necessários para que o projeto de políticas editoriais da RISC venha a se adequar às normas internacionais de fazer e comunicar a pesquisa científica?

O presente trabalho enquadra-se como pesquisa bibliográfica por meio de estudo de natureza qualitativa. A pesquisa bibliográfica é uma modalidade de estudo e análise de documentos de domínio científico tais como livros, periódicos, enciclopédias, ensaios críticos, dicionários e artigos científicos. (Oliveira, 2013).

\section{Referencial Teórico}

\subsection{Identificação de boas práticas editoriais}

\subsubsection{As boas práticas na publicação científica}

As boas práticas na publicação científica e o processo editorial, depois da ocorrência da parte formal, assegura que os pesquisadores revisem e concordem comprovadamente a responsabilidade pelo trabalho e fichem a participação de cada um. É possível registrar por meio de assinatura ou confirmação digital, e deve demonstrar também se há conflito de interesses, que deve ser evidenciado na publicação.

Quando há controvérsias relacionadas à autoria, primeiramente se contata o autor correspondente e, quando necessário, com todos os autores. Em caso de dúvidas, contata-se as instituições de afiliação dos mesmos ou de financiamento envolvidas no desenvolvimento do projeto.

Quanto aos participantes envolvidos na pesquisa, o processo editorial pede que os escritores demonstrem antecedentes, como por exemplo parecer do comitê de ética correspondente, autorização dos sujeitos envolvidos, registros de ensaios clínicos, entre outros. Quando há divergências ou questionamento, o editor-chefe contata o autor e, se necessário, com todos os pesquisadores pedindo as informações que estiverem pendentes. Para proporcionar a originalidade dos textos o periódico adere a programas de verificação de duplicidades com trabalhos já publicados. O periódico informa aos escritores o programa em uso no momento da submissão dos trabalhos.

\subsubsection{Declaração de boas práticas com foco na ética da publicação}

O Comitê de Ética em Publicações (COPE), o Diretório de Revistas de Acesso Aberto (DOAJ) e o Programa SciELO, são instituições que juntas, trabalham em colaboração entre si, com o propósito de construir princípios de transparência e boas práticas nas publicações acadêmicas e para evidenciar que esses princípios constituem a base dos critérios pelos quais o COPE, DOAJ e Scielo avaliam a adequação para adesão de novos autores.

Cada entidade possui seus critérios que são utilizados na avaliação das solicitações. Para que os editores ou periódicos constem das listas compartilhadas por estas organizações é necessário que cumpram os critérios de transparência e boas práticas.

O COPE sugere aos editores seguir integralmente os aspectos da ética na publicação e sobre como lidar com prováveis 
casos de más condutas na pesquisa e na publicação e esperando que todos os membros apliquem os princípios de ética descritos nas práticas principais.

\subsection{Padrões do processo editorial}

\subsubsection{Estrutura gerencial e editorial}

O foco desde o início para um periódico científico é conseguir conduzir até seus leitores o conhecimento novo e importante para seu nicho de atuação. Principalmente conseguir fazê-lo tempestivamente e buscar perpetuar-se. (Trzesniak, 2009). Para ele:

A preocupação primeira e principal e a tempestividade são garantidas pelo processo editorial, uma série de tarefas sequenciais, que devem ser executadas de modo sistemático e eficiente. Esse processo deve, também, ser transparente, ou seja, na medida do possível, oferecer a possibilidade de acompanhamento pelas partes envolvidas. Já a perenidade se configura pela existência de uma sólida retaguarda institucional, de um Comitê de Política Editorial e de um regulamento que contempla a sucessão/escolha do editor e a estrutura científica do periódico (Trzesniak, 2009).

\subsection{Responsabilidades do editor-chefe}

O editor-chefe possui responsabilidades que compreendem desde a implementação da política editorial, ao acompanhamento e supervisão do processo editorial. Também as relações com os autores, pareceristas, leitores, indexadores e o público de maneira geral. O compromisso com os bons valores para o andamento adequado do processo e também é essencial o controle de qualidade e a transparência.

\subsection{O papel do editor}

$\mathrm{O}$ editor dirige o processo editorial e propicia o desenvolvimento dos autores e avaliadores da publicação. Carrega o compromisso de oferecer o que houver de melhor em termos de conhecimento novo dentro da área de atuação, sempre prezando, no processo de seleção dos artigos, pela ética.

As Boas Práticas preconizam que a escolha do editor de um periódico seja supervisionada pelo Comitê de Política Editorial, e que considere diversos fatores, entre os quais: liderança como pesquisador da área, reconhecimento da comunidade, histórico de atuação como revisor e autor e seu projeto de trabalho para o periódico (Trzesniak, 2009).

Segundo a ANPAD (Associação Nacional de Pós Graduação e Pesquisa em Administração), há ênfase na importância da credibilidade do editor na escolha dos artigos, porque a publicação em periódico está significativamente atrelada ao êxito na caminhada acadêmica dos autores (Shapiro \& Bartunek,2008). Para esses escritores, mostra-se trivial que as pessoas que trabalham como editores apresentem competência para elaborar estudos e revisões com excelência; cordialidade em relação a pesquisadores recentes e outros especialistas da área técnica do conhecimento; imparcialidade, dignidade e regularidade como geradores, avaliadores e mentores de estudos de excelência.

O editor é responsável pelo que é divulgado em seu periódico. Ao deliberar que possivelmente vai aprovar a publicação de uma pesquisa, ele deve analisar integralmente o trabalho, inclusive sendo recomendado que faça sugestões e veja com os escritores a elaboração de alterações que acredite ser necessária, em prol da transparência e clareza na veiculação de ideias e do rigor científico - entretanto deve propor sem interferir na forma de trabalho dos autores (Botsford, 1993).

Uma outra razão que pode acarretar na recusa imediata de um paper, e que deve também ser observado na revisão de admissão, é a ausência de ineditismo do trabalho. Além de conferir em livros e em outras revistas, é necessária a verificação do editor em casos de re submissão ao seu próprio periódico. 
$\mathrm{O}$ editor deve estar seguro de que o material de pesquisa que publicar esteja em conformidade com normas éticas internacionalmente aceitas e deve tomar todas as medidas para garantir a qualidade do material que publica e assim não permitir que interesses individuais e de instituições que patrocinam o periódico comprometam os respectivos padrões acadêmicos.

Se, após a devida análise, em algum artigo é encontrada fraude, este deve ser recolhido. A exclusão deve ser identificável para leitores e sistemas de indexação. Assim, todas as vezes que o editor reconhecer que um material impreciso, enganoso ou distorcido foi publicado, ele deve rapidamente tomar providências para resolver o problema prontamente e com o devido destaque.

\subsection{0 autor}

Listou-se alguns pontos representativos, inspirados em Moizer (2009), Konrad (2008), Ryan (2008) e COPE (2010), que podem ser úteis para os escritores terem mais sucesso em suas iniciativas de publicação de manuscritos. Submeter trabalhos apenas quando gramaticalmente revisados e de acordo com as normas para formatação, citações e referências estabelecidas nas instruções aos escritores do periódico. Ignorar esses pontos causa rejeição na revisão de aceite. Exibir com clareza as ideias, inclusive a utilização adequada de ilustrações e referências. Os trabalhos precisam estar de acordo com o formato do periódico e são comumente formados pelas seguintes partes: a introdução, que inicia o texto e introduz a finalidade da pesquisa (a razão pela escolha do tema, a problematização, e os objetivos do projeto) e aborda sua relevância; o referencial teórico; a metodologia; resultados e discussão; conclusões e recomendações; e referências meticulosamente revisadas em cumprimento ao padrão estabelecido pelo periódico.

É uma infração ética grave submeter um mesmo manuscrito a mais de um periódico ou enviá-lo a um novo periódico sem retirá-lo formalmente de algum outro em que o texto esteja sendo avaliado e sem dúvidas inadequado, sob ponto de vista ético, efetuar a submissão de um manuscrito com limitações conhecidas pelos autores, que poderiam perfeitamente ser por eles corrigidas, na expectativa de que seja aceito apesar dessas limitações ou com o propósito de transferir a editores e revisores a função de melhorá-lo.

\subsection{Papel do Comitê de Política Editorial, ou Conselho Editorial, e do Corpo Editorial Científico}

Para estar de acordo com as boas práticas, um artigo carece de possuir duas instâncias coletivas: o Comitê de Política Editorial, ou Conselho Editorial, e o Corpo Editorial Científico.

Então unindo as conceituações de Lo Bianco et al. (2002) e de Trzesniak (2001, 2009), o COE é formado pelo Editor e por outros membros que simbolizam democraticamente os interesses da área do conhecimento; das organizações que garantem a credibilidade científica do periódico; e das que o fundamentam de acordo com a lei. Esse Comitê cuida dos assuntos relacionados à administração política editorial da revista e atua em conjunto, assumindo decisões coletivas e, ocasionalmente, elegendo matérias; não tendo o envolvimento com qualquer fascículo ou artigo em particular, mas com toda a coletânea, estabelecendo as diretrizes gerais que a norteiam.

O Corpo Editorial Científico é um colegiado multi-institucional, composto por especialistas tanto no assunto científico, percorrendo as áreas de conhecimento de que trata o periódico, como geográficos, ou seja, abrangendo as diferentes regiões do Brasil e também de outras nações. Distintamente dos componentes do Comitê de Política Editorial, os do Corpo Editorial Científico operam individualmente e têm relação considerável com o teor dos fascículos do periódico, preocupando-se com a uniformidade, continuidade e rigor científico de tudo o que é publicado. 


\section{Metodologia}

O Projeto editorial é um documento bastante importante no processo de editoração, como norteador, ainda mais no período contemporâneo no contexto de grandes mudanças tecnológicas, pois é nele que encontramos os direcionamentos necessários para que o desenvolvimento do trabalho realizado da forma mais satisfatória possível, é importante a adoção de um projeto editorial bem formulado, já que o mesmo servirá como documento norteador do perfil e das políticas editoriais a serem adotadas pelo periódico.

Visando obter um resultado satisfatório na pesquisa, foi feito uma revisão bibliográfica sobre aspectos relacionados com a comunicação científica através de publicações periódicas, levando em consideração as grandes mudanças ocorridas no contexto editorial, principalmente no que se refere ao avanço tecnológico tão evidente no mundo contemporâneo. A pesquisa bibliográfica é caracterizada como de natureza aplicada, segundo Kauark (2010) quando objetiva fornecer conhecimentos para aplicação prática, dirigida à resolução de problemas específicos. A abordagem do problema é qualitativa e procura compreender um fenômeno específico em profundidade por meio de comparações e interpretações ao invés de estatísticas, regras e outras generalizações (Marconi \& Lakatos, 2003). Já quanto aos objetivos, a pesquisa é classificada como descritiva que, de acordo com Hair Junior et al. (2005), apresenta planos organizados e especificamente criados para medir as características descritas em uma questão de pesquisa.

Foi realizado um estudo utilizando uma abordagem comparativa entre algumas das melhores revistas brasileiras conforme a classificação Qualis - CAPES, e serão usadas como exemplo.

\subsection{Estudo de análise comparativa entre periódicos}

\subsubsection{Abordagem comparativa}

Para a elaboração da pesquisa foi primeiramente realizado um estudo utilizando uma revisão bibliográfica entre algumas revistas classificadas na base de dados Qualis como A1.

A comparação se deu com a finalidade de selecionar, segundo o CAPES, quais revistas brasileiras, entre as escolhidas, mais conceituadas na área de Ciência da Informação, para que possamos direcionar as melhores práticas encontradas, tanto no quesito Boas Práticas como também na Ética, para a revista em questão a RISC. As revistas selecionadas para a abordagem comparativa foram:

\section{a) Revista 1 - Transinformação}

O periódico científico Transinformação foi fundado pela PUC - Campinas (Pontifícia Universidade Católica), em 1989. Especializado em publicar colaborações inéditas na área de Ciência da Informação e Ciências de domínio conexo. Seu sítio, http://revistas.puc-campinas.edu.br/transinfo/index.php, traz informações completas sobre os procedimentos executados na revista, os quais são discutidos neste tópico. Seu conteúdo é integralmente em acesso aberto digital, com periodicidade quadrimestral, aceitando colaboração de caráter inédito de pesquisadores nacionais e internacionais, e distribuídas no território nacional e internacional. Caracteriza-se pela contínua busca de qualificação científica, participando de comissões editoriais no território nacional e internacional. Está indexada na Web of Science, base de dados de visibilidade internacional, com artigos a partir de 2008. Possui regras de seleção e avaliação que possibilitam o acesso público a submissão de artigos, processo de avaliação por pares com sistema de blind review, que é uma técnica que propicia o sigilo quanto à identidade tanto dos escritores quanto dos revisores, Indexação para busca e ferramenta de apoio à pesquisa. Pela busca da visibilidade e qualidade, o periódico apresenta duas políticas de grande importância para comunidade científica, a de acesso público de todo o seu conteúdo, gerando maior intercambio global de conhecimento, e de arquivamento para preservação, utilizando o sistema LOCKSS para distribuição entre bibliotecas, para criar arquivos permanentes da revista (TRANSNFORMAÇÃO, 1989). A Transinformação é classificada 
como um dos periódicos mais relevantes entre seus pares, com categorização de Qualis A1 em agosto de 2012, pela CAPES. A Transinformação está indexada nas seguintes bases de dados, segundo seu próprio site: Social Science Citation Index, Web of Science, Latindex, CLASE. No portal todo seu conteúdo pode ser encontrado na íntegra.

\section{Foco e Escopo}

É aberta à colaborações científicas nacionais e internacionais, editada pela Faculdade de Biblioteconomia do Centro de Ciências Humanas e Sociais Aplicadas da PUC-Campinas, está classificada na lista Qualis como A1, publica artigos científicos originais que cooperam com o estudo e desenvolvimento científico da Ciência da Informação, Biblioteconomia, Arquivologia, Museologia e áreas afins

\section{Periodicidade}

Trimestral

\section{Indexadores}

Social Science Citation Index, Web of Science, LATINDEX, CLASE

\section{Pesquisa do conteúdo}

Pode ser feita por: edição, autor, título, outras revistas

\section{Idioma}

Português, Inglês e Espanhol

\section{Política antiplágio}

Exige a originalidade dos artigos submetidos

\section{Tipo de artigos}

Trabalhos relacionados a área da Ciência da Informação, Biblioteconomia e áreas afins

\section{Política de submissão}

Adota a revisão por pares com sistema de blind review, em procedimento sigiloso quanto à identidade tanto dos autores quanto dos revisores

\section{Política de avaliação}

Utiliza normas de seleção e avaliação que permitem o acesso público à submissão de artigos

\section{Política de acesso}

Acesso público de todo o seu conteúdo, gerando maior intercambio global de conhecimento

\section{Política arquivamento para preservação}

Por meio do sistema LOCKSS para distribuição entre bibliotecas, propiciando a elaboraçã de arquivos permanentes da revista

\section{b) Revista 2 - Informação \& Sociedade}

Informação \& Sociedade: é publicada desde 1991 quando foi criada pela UFPB - Universidade Federal da Paraíba, sendo uma das primeiras a ter trabalhos científicos publicados no Portal de Periódicos da UFPB. É no momento uma das três revistas brasileiras da área de Ciência da Informação que fazem parte do Journal Citation Reports (JCR Web) do Institute for Scientific Information (ISI Web of Knowledge).

Tem a missão de veicular projetos que contribuam com o desenvolvimento de novos conhecimentos em Ciência da Informação, Biblioteconomia e áreas afins, entre pesquisadores, docentes, discentes e demais profissionais, independente de vinculação profissional e local de origem.

Possui abrangência nacional e internacional, como é percebido, e detém a revisão por pares. Porque faz parte das publicações vinculadas ao Programa de Pós-Graduação em Ciência da Informação da UFPB, a revista tem uma política editorial de distribuição da produção local de modo a não privilegiar a produção apenas interna, promovendo a equidade.

A política editorial da I\&S está aberta às variadas perspectivas pelas quais os cientistas da informação observam a Informação na Sociedade. Sua expectativa é que a revista siga cooperando para trocas comunicativas sobre relatos de estudos, 
reflexões e proposições dos pesquisadores da informação do Brasil e do mundo.

\section{Foco e Escopo}

Objetiva publicar trabalhos que contribuam com crescimento sistêmico, os resumos das dissertações aprovadas no PPGCI/UFPB. A revista requisita originalidade dos artigos submetidos e que, pelo menos um dos autores tenha titulação de doutor.

\section{Periodicidade}

Quadrimestral, publicada nos meses de abril, agosto e dezembro

\section{Indexadores}

Portal da CAPES, INFOBILA, LISA, CLASE, LATINDEX e OAIster

\section{Pesquisa do conteúdo}

Pode ser feita por: edição, autor, título, outras revistas

\section{Idioma}

Português, Inglês e Espanhol

\section{Política antiplágio}

Exige a originalidade dos artigos submetidos e que, pelo menos um dos autores tenha titulação de doutor

\section{Tipo de artigos}

Trabalhos relacionados a área da Ciência da Informação, Biblioteconomia e áreas afins

\section{Política de submissão}

Adota a estrita revisão por pares

\section{Política de acesso}

Acesso livre

c) Revista 3 - Perspectiva em Ciência da Informação

A Revista Perspectivas em Ciência da Informação foi criada em 1996, e é classificada no Qualis com o conceito A1 Sua temática é dirigida a profissionais e cientistas da área educacional com o propósito de tratar questões atuais e significativas em seu campo de atuação. A Revista Perspectivas em Ciência da Informação concede acesso livre e tem periodicidade trimestral. Está indexada em importantes bases de dados como a SciELO, Directory of Open Access Journals, INFOBILA - Base de Datos de Información y Bibliotecología Latinoamericana, Information Science Abstracts, INSPEC, International Bibliographie der Rezensionen Wissenschaftlicher Literatur, ISI Web of Knowledge, Latindex, Library and Information Science Abstracts, Library Literature, LICI - Literatura de Ciência da Informação, PASCAL, Scopus.

Os trabalhos submetidos à Perspectivas em Ciência da Informação são encaminhados a três membros dos Conselhos Editorial e Consultivo que decidem sobre sua aceitação ou recusa, sem que sua autoria seja divulgada.

\section{Foco e Escopo}

Perspectivas em Ciência da Informação é uma publicação trimestral da Escola de Ciência da Informação da UFMG, lançada em 1996, em substituição a Revista da Escola de Biblioteconomia da UFMG, com publicações datadas de 1972 a 1995. Divulga artigos científicos, relatos de pesquisa, estudos teóricos, revisões de literatura, relatos de experiências, traduções e resenhas em Ciência da Informação, Biblioteconomia, Arquivologia, Museologia e áreas afins.

\section{Periodicidade}

Trimestral

\section{Indexadores}

SciELO, DOAJ, INFOBILA, ISA, INSPEC, ISI, Latindex, LICI 


\section{Pesquisa do conteúdo}

Pode ser feita por: edição, autor, título, outras revistas

\section{Idioma}

Português, Inglês e Espanhol

\section{Política antiplágio}

Exige a originalidade dos artigos

\section{Tipo de artigos}

Trabalhos relacionados a área da Ciência da Informação, Biblioteconomia e áreas afins

\section{Política de submissão}

Trabalhos encaminhados a três membros dos Conselhos Editorial e Consultivo que decidem sobre sua aceitação ou recusa, sem que sua autoria seja divulgada

\section{Política de acesso}

Acesso livre

\section{Resultado}

A análise utilizada foi a técnica de estudo comparativo entre três dos mais conceituados periódicos na área de Ciência da Informação. A operacionalização dos dados foi realizada em duas etapas: a análise das Boas Práticas de Publicações Científicas, e a aplicação dos princípios de Transparência e Ética nas publicações.

A finalidade desta análise comparativa é a provável aplicação dos resultados positivos obtidos na reformulação da RISC, razão motivacional para a execução deste trabalho. A seguir uma breve apresentação dos documentos abordados na seleção das boas práticas e ética na editoração de artigos científicos, são eles: SciELO, COPE e DOAJ.

\subsection{Guia de boas práticas para o fortalecimento da ética na publicação científica - Conforme a Scielo}

O guia de boas práticas serve de padrão para os periódicos das coleções da Rede SciELO. O programa SciELO segue normas e recomendações de padrões de ética e responsabilidade na comunicação científica elaboradas pelas instituições nacionais e internacionais, entre as quais se destacam: COPE, CSE, Equator Network, ICMJE, CNPq, Fapesp e o Manual de Boas Práticas para o Fortalecimento da Ética na Publicação Científica do SciELO e assim promove a integridade e transparência em seu processo de avaliação de artigos e na reprodutibilidade da pesquisa, sobre a ocorrência de manipulação ou invenção de dados, plágio, conflitos de interesse ou de autoria.

Os critérios para a inclusão de periódicos científicos na base SciELO são o caráter científico; em que é exigido que os periódicos publiquem, predominantemente, trabalhos originais resultantes de pesquisa científica e é feita a arbitragem por pares. O banco Scielo registra, e assim que indexa um periódico após o processo. É necessário registrar as principais datas do processo de inserção de um artigo, indicando-se a data de recebimento e aprovação.

A formação do conselho editorial tem suma importância para a indexação de um periódico, sendo que seus integrantes devem ter conhecido saber, de origem nacional e internacional. São rechaçados periódicos que possuem corpo editorial com integrantes ligados a uma instituição e que seus artigos majoritariamente tenham sido publicados emuma única instituição ou região geográfica. Evidencia tabela de indicação da periodicidade, de acordo com a área do periódico. (SciELO - Scientific Electronic Library Online- http://www.scielo.br/ ).

\subsection{Princípios de Transparência - conforme a COPE}

O papel do COPE é suportar os editores de periódicos acadêmicos e editores / proprietários - assim como outros partidos, como instituições e financiadores, ainda que de forma menos direta - em seus esforços para manter e desenvolver a integridade do registro acadêmico por meio de de políticas e práticas que demonstram os melhores princípios de transparência. As novas 
recomendações do COPE buscam refletir esses objetivos, de maneira objetiva. (Comitê de Ética na Publicação 2018).

\section{Conclusão Final}

\subsection{Proposta de Projeto Editorial para a RISC}

Para que todas as decisões fossem tomadas, se fez necessário repensar o contexto em que a revista se encontra e que mudanças deveriam ocorrer a fim de que a RISC viesse a ter a visibilidade e credibilidade esperada na sua área específica da Ciência da Informação. Nesta fase, foi proposto uma análise comparativa entre as revistas mais conceituadas na área da Ciência da Informação e a RISC, com o fim de analisar parâmetros entre elas no que diz respeito às Boas Práticas de Editoração, Princípios de Transparência e Ética. Esta análise consiste em verificar a aplicação dessas normas de conduta já utilizadas por essas revistas em comparação com o que hoje é visto na RISC. A proposta então é tentar traçar um roteiro onde a RISC venha a ser mais atuante, nessa área tão relevante para o sucesso de um periódico científico. Deste modo, quanto aos objetivos específicos: Identificar boas práticas editoriais em periódicos selecionados da área da Ciência da Informação no Brasil e com foco na ética da publicação em documentos de organismos nacionais e internacionais, a conclusão foi a seguinte:

1) A sua política de submissão deve estar atenta para seguir as normas mais atuais e sempre buscando padronização internacional, objetivos e normas editoriais,

2) Processo de avaliação pelos pares: Os originais deverão ser submetidos à aprovação de avaliadores, especialistas reconhecidos e de conhecido saber, na respectiva área de atuação,

3) Política de acesso livre: Esta revista oferece acesso livre imediato ao seu conteúdo,

4) Contato da equipe editorial: Consta no site da revista os nomes completos dos editores, conselho editorial, bibliotecário e corpo editorial científico; suas afiliações e o contato.

\subsection{Aumento na visibilidade}

Apesar de todo o trabalho de pesquisa ter se concentrado na aplicação das normas de boas práticas, transparência e ética, fez-se necessário a sugestão da aplicação de ferramentas e recursos ligados ao Marketing Eletrônico que possibilite ampliar a visibilidade da Revista RISC, O Marketing é um fator primordial para o aumento da visibilidade e consequente divulgação das pesquisas, ampliando, ainda mais, o leque de buscas do periódico à nível nacional e internacional, auxiliando na divulgação dos artigos, pesquisadores e consequentemente suas instituições.

Com o intuito de garantir os direitos autorais aos autores e facilitar ao usuário ampla utilização de materiais, sem infringir as leis de proteção à propriedade intelectual do autor, sugere-se implementar na RISC a ação que visa disponibilizar os artigos científicos, sob a licença Creative Commons.

É de fundamental importância para o periódico, a adoção de uma política antiplágio devendo ser cuidadosa ao identificar más condutas e devendo rejeitar a publicação de documentos nos quais se tenha identificado plágio. Caso tenha conhecimento de más condutas relacionadas a algum artigo publicado na RISC, o editor deve seguir as diretrizes do COPE (ou equivalente) no tratamento dessas acusações.

\subsection{Indexação em base de dados}

A ação de indexação da Revisa RISC em bases de dados, portais eletrônicos e bibliotecas digitais possibilita melhorar o acesso e localização dos artigos, ampliando a possibilidade de serem lidos, citados e divulgados. Entre os repositórios para indexação recomendados são: Directory of Open Access Journals (DOAJ); o Sistema Regional de Información en Línea para Revistas Científicas da América Latina, Caribe, Espana e Portugal (Latindex); a Bibliothèque de l'Université de Nice 
SophiaAntipolis e a Academic Journals Database, entre outros.

\section{Considerações Finais}

Diante do exposto sugere-se aplicar o modelo de gestão de periódicos científicos eletrônicos encontrado nas revistas: Transinformação, Informação \& Sociedade e Perspectiva em Ciência da Informação, que serviram de base para a nossa pesquisa bibliográfica, com o propósito de fazer uma análise comparativa e verificar diferentes resultados; aplicar o modelo encontrado com relação as Boas Práticas na Editoração, Transparência e Ética, como também no quesito à visibilidade através do Marketing Digital.

\section{Referências}

ABNT - Associação Brasileira de Normas Técnicas. (2003). NBR 6022: Artigo em publicação periódica cientifica impressa. ABNT.

Andre, C. S. (2012). Análise bibliométrica do periódico científico transinformação. Trabalho de Conclusão de Curso de Graduação em Biblioteconomia, do Centro de Ciências Sociais da Educação da Universidade Federal de Santa Catarina. Florianópolis.

Araújo, E. (2008). A Construção do Livro. (2a ed.), Lexicon.

Araújo, V. M. R. H. (1991). Informação: instrumento de dominação e de submissão. Ciência Da Informação, 20(1). Recuperado de http://revista.ibict.br/ciinf/article/view/414.

Bomfá, C. R. Z. (2009). Modelo de gestão de periódicos científicos eletrônicos com foco na promoção da visibilidade.

Botsford, G. (1993). Remembering Mr. Shawn. The New Yorker (dec. 28, 1992/jan. 4, 1993), 139.

Brasil, C. S. (2010). Critérios, política e procedimentos para a admissão e a permanência de periódicos científicos na Coleção Scielo Brasil. Scielo Brasil.

Carvalho, A. F. B. (2010). Pode chamar de G: notas sobre um projeto editorial. Anagrama, 4(1), 1-10.

COPE - Committee on Publication Ethics. (2018). Recuperado de www.publicationethics.org.

Ferreira, S. M. S. P., \& Targino, M. das G. (2005). Preparação de revistas científicas: teoria e prática. Reichmann \& Autores.

Hair, J., Babin, B., Money, A., \& Samouel, P. (2005). Fundamentos de métodos de pesquisa em administração. Bookman Companhia Ed.

Kauark, F. D. S., Manhães, F. C., \& Medeiros, C. H. (2010). Metodologia da pesquisa: um guia prático.

Marconi, M. D. A., \& Lakatos, E. M. (2003). Fundamentos de metodologia cientifica. (5a ed.), Atlas.

Meadows, A. J., \& de Lemos Lemos, A. A. B. (1999). A comunicação científica. Briquet de Lemos/livros.

Medeiros, G. L. B., \& Medeiros L. P. M. (2021). Ausência de educação financeira no Brasil: O impacto à sociedade e a possibilidade de reversão. Brazilian Journal of Development, 7(10). https://doi.org/10.34117/bjdv7n10-449.

Mueller, S. P. M., \& Pecegueiro, C. M. P. D. A. (2001). O periódico Ciência da Informação na década de 90: um retrato da área refletido em seus artigos. Ciência da informação, 30, 47-63.

Oliveira, M. M. D. (2013). Como fazer pesquisa qualitativa. In Como fazer pesquisa qualitativa (pp. 232-232).

Packer, A. L. (2011). Os periódicos brasileiros e a comunicação da pesquisa nacional. Revista USP, (89), 26-61.

Rosetto, M. (1997). Os Novos Materiais Bibliográficos e a Gestão da Informação: livro eletrônico e biblioteca eletrônica na América Latina e Caribe. Ciencia da informaçao, 26, 54-64. https://doi.org/10.1590/S0100-19651997000100008

Scielo. (2017). Guia para o registro e publicação de retratação. http://ref.scielo.org/zgrrv8.

Shapiro, D. L., \& Bartunek, J. (2008). Being an ethical editorial board member and editor: The integral role of earned trust. In Opening the black box of editorship (pp. 88-96). Palgrave Macmillan, https://doi.org/10.1057/9780230582590_9

Souza, S. L. (2009). Coleções em bibliotecas universitárias: revelações da produção científica.

Trzesniak, P. (2009). A estrutura editorial de um periódico científico. Publicar em psicologia: um enfoque para a revista científica. Associação Brasileira de Editores Cientificos de Psicologia, 87-102.

Weitzel, S. R. (2005). Revendo critérios referentes à revista eletrônica. Ferreira, S.\& Targino, M. G. Preparação de revistas científicas-teoria e prática. Reichmann \& Autores, 161-193. 